It was alsa ascertained that this material of deficient density probably extends to a depth of about seventy miles below the surface.

The flattening of the earth, according to this investigation, is between the values assigned by Clarke and Bessel. Both the equatorial and the polar dimensions are found to be larger than they were stated to be by
Bessel or Clarke, or any of the other principal investigators along this line.

\section{HYBRIDIZATION OF THE OAKS.*} By Dr. D. T. MaCDougal.

THE number of forms of plants which have been or are regarded as hybrids by systematists is a large been examined in the last two seasons. Attention has been previously called to the untrustworthiness of the custom prevalent among botanists of attributing a hybrid origin to certain plants because they aping a hybrid origin to certain plants because they ap-
pear to exhibit halved, fused characters or a mosaic of qualities derived from the two supposititious ancestors. In some instances such deductions have been made by which the ancestry of a questionable plant has been made to include three or even four species. The argument of distribution is the main one offered in such attempted demonstrations. In some instances, this together with other circumstantial evidence may amount to almost positive conviction, but unless this tions as to the hybridity of a plant must be taken simply as a suggestion to be tested by cultural or experiply as a susestion to be tester ing the flora of North America made by Mr. D. S. Geore in 1903 brought to lisht referes seed plants.

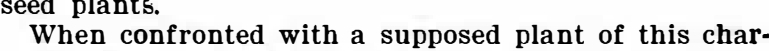
acter, three methods of attack are available to the investigator: that of obtaining the supposed hybrid by synthesizing it from its supposed parents; that of making an anatomical examination of the hybrid and the parents to which it has been referred; and that of obtaining second, third, and succeeding generation of the hybrid for the purpose of ascertaining whethe or not any separation of the ancestral characters may
occur in an alternative inheritance, by which the ancestral forms may actually reappear. All of these methods are beset with numerous difficulties, but when used together with the facts of distribution
very satisfactory degree of proof may be obtained. very satisfactory degree of proof may be obtained.
The re-formation of a hybrid by the cross pollenation of the parents to which it may be ascribed is by no means simple in all instances, nor is it always easy of accomplishment. In the first place the original cross pollenation may have possibly taken place under an exceedingly rare combination of favorable
physiological conditions difficult to secure or duplicate as ordinarily recognized may in reality consist of two or more elementary species, which may not differ widely in - external anatomical characteristics, bu
which may offer widely divergent physiological char which may offer widely divergent physiological charhybrid with one of these forms may differ in very many important particulars from a hybrid with another constituent of the same species. Of course if we deal with elementary species only in our usage of
the term this difficulty does not exist, but it does appear as a serious matter with the customary practice, as has been found in a number of breeding experiments, and furthermore must be taken into account no matter by what method we consider a hybrid. hand the two strains or elementary species by which the hybrid may have arisen, and we have still one more matter which may mislead us. This consists in the fact that reciprocal crosses are not always identical in their products. Thus the pollen of $\mathrm{A}$ and the egg of $B$ do not give us

The pollenation of Oenothera Lamarckiana by 0 . biennis generally results in securing a progeny separable into seven types, some of which are fixed and reproduce themselves exactly in succeeding generasecond generation. On the other hand, the use of pollen of 0 . Lamarckiana on pistils of O. biennis results in a progeny embracing four types, none of which is identical with the components of the reciprocal cross. 0 . biennis shows a similar behavior in some other crosses in the limited observations re the number of types does not appear to be fixed, an that a progeny of a hundred thousand is likely to include more than one of a score. It is evident that in the determination of a hybrid by this method difficulties may be met with. Thus failure of the operator to secure the supposed hybrid may not be considered as proof that it may really have come by one of the
rarer combinations which he has missed. On the other hand, success may come with the first cross and in the first generation.

In some instances the result of a hybridization is a locked in a stable offers the qualities of the parent combination in the first generation erations. It is this type of hybridization that is im plied in the general assertions as to the hybrid origin of any plant, and it is a type of which we have the fewest illustrations in breeding experiments.

To recur again to the genus furnishing the example

*Paper read before the American Aseociation for the Advancement of previously given, 0 . cruciata varia was suspected by the author to be a combination of 0 . Lamarckiana an o. cruciata, and in the synthesizing test the good fortune was encountered of selecting the one of the three known elementary species of 0 . cruciata which had originally entered into the union. The egg of $L a$. marckiana and the pollen elements of this form en-
tered into a stable combination which has the distinctness and fixity of a species, and as a matter of fact this hybrid has been long mistaken for the true o. cruciata by a great number of European gardeners and botanists.

In addition to the difficulties of hybridization and interpretation of the results described above, it is also to be taken into account that in some instances a long period ensues between the act of pollenation and the perfection of the fruit, and then a long time is neces sary for the germination of the seeds and develop ment of the progeny. Ten, fifteen, or even twenty
years might be necessary to make an application years might be necessary to make an application of
this method to some of the species of trees, which would obviously make it unavailable except under ex traordinary circumstances.

The examination of the anatomical characters of a plant to determine its ancestry is a method which has become of less esteem in the light of modern additions to information as to the character and behavio of hybrids. Of the various types of hybrids described, it is of course the fixed hybrid which is most likely to
come under examination; and while it occasionally come under examination; and while it occasionally
presents a fair average of the characters of the parent, presents a fair average of the characters of the parent,
yet more frequently it is goneoclinic to one or the yet more frequently it is goneoclinic to one or the
other, and may be so near one parent that a gross or other, and may be so near one parent that a gross or
minute estimation of the tissue structure would offer minute estimation of the tissue structure would offer nothing better than a guess as to the other parent, a
guess which might be fortified to some extent by the guess which might be fortified to some extent by the
facts of distribution perhaps. In certain meristic
qualities such as the rate and total amount of growth

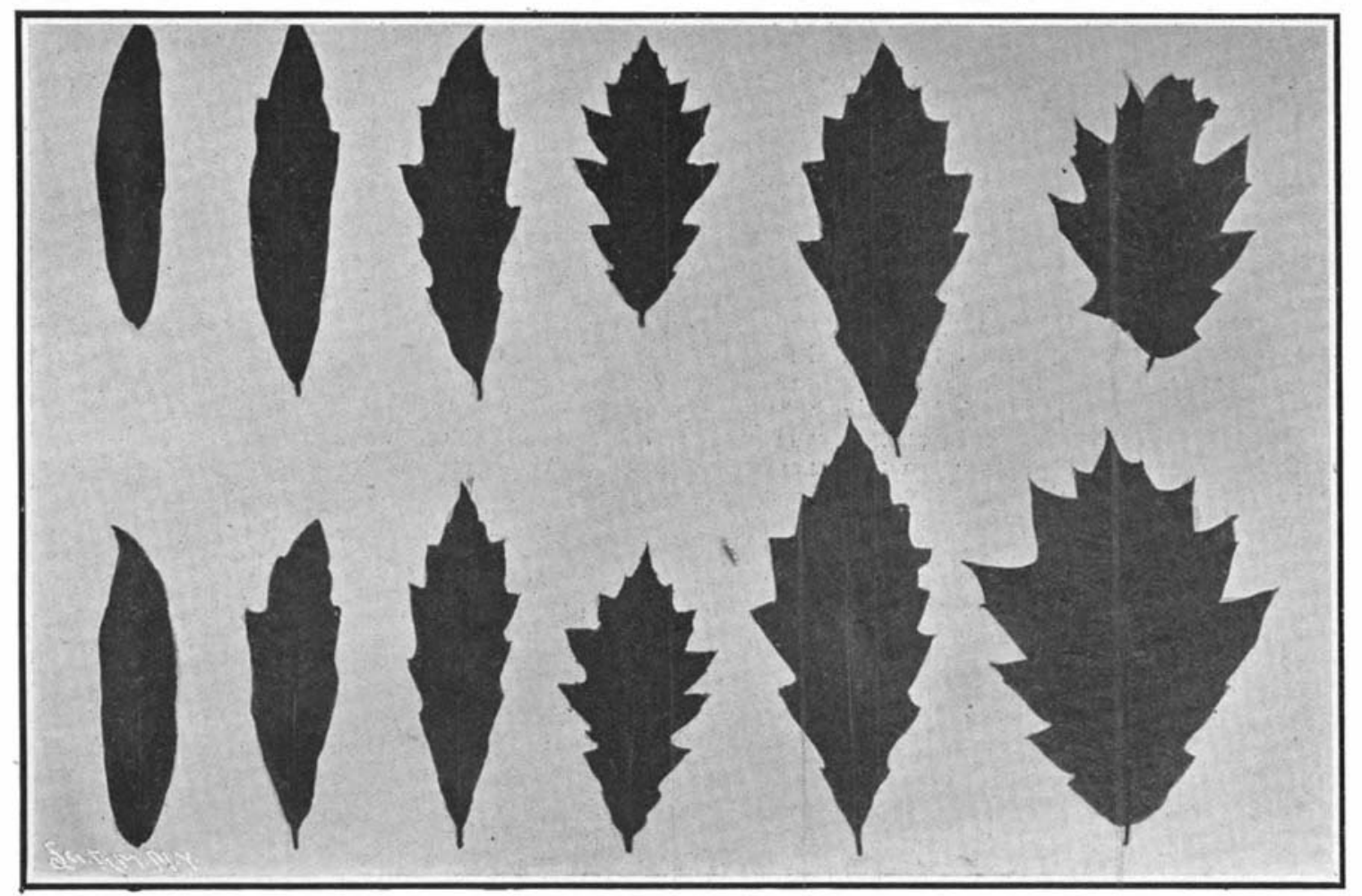

HYBRIDIZATION OF THE OAKS.

the hybrid may even exceed that of either parent or

The mistaken impression prevails that hybrids bea defective pollen, but this is generally found to be th case only when the cross is unbalanced in many char-
acters, particularly those appertaining to the reproacters, particularly those appertaining to the repro-
ductive functions. The infertility of many animal hybrids has also strengthened the assumption that plant hybrids share this defect. Many hybrids are quite as prolific in mature seeds as either parent, while in some that are offered by the seedsman and nurseryman they are claimed to excel in this respect. In any case where the comparative anatomical servations upon material from similar stages of development. This is forcibly impressed upon one after following the growth of a hybrid which in the seedling stages shows a predominance of the qualities and anatomical characters of one parent, a different arrangement in the adult shoot, and a still different balance in the flower and fruit.

The third method of study of a supposed hybrid is one which involves pure cultures of its progeny for one or two generations. If it should be a fixed hybrid the solution of the problem, since so far as any facts offered by such cultures are concerned the plant behaves as any other species. Presumably most of the haves as any other species. Presumably most of the ter, but some of them will be undoubtedly found to be constantly re-formed and to offer alternative inheritance, and hence this test should be applied whenever practicable.

If the supposed parents differ in but one or a few characters and the hybrid shows alternative inherhand. It is not such simple questions as this, however, that we are usually called upon to solve. The real difficulties lie with hybrids with the component qualities in stable combination making a fixed hybrid and with the forms which exhibit an interlocked com. bination of the ancestral characters in the first genera.
tion- which resolve into the possible combinations of the dissimilar characters in the second, by which an enormous range of individuals is presented, which without close examination of a large progeny might appear to be a hopeless medley. This is best illus-
trated by a plant which has been recently studied in trated by a plant which has been recently studied in
cultures at the New York Botanical Garden and at the cultures at the New York Botanical Garden and at the
Desert Laboratory-Bartram's oak, Quercus hetero. phylla.

Bartram's oak was discovered as a single individual growing on the farm of Mr. John Bartram near Philadelphia, on the banks of the Schuylkill, at some time previous to 1750 . A rather complete history of the occurrence of other individuals which were included
with this tree under the name of Q. heterophylla is given by Dr. Arthur Hollick in the Bulletin of the Torrey Botanical Club for 1888 (15:303. 1888) and need not be repeated here.

After a consideration of various lots of material which appeared to differ widely, various botanists have
regarded this tree as a hybrid between $Q$. Phellos and Q. tinctoria, Q. Phellos and Q. falcata, Q. Phellos and $Q$. coccinea, $Q$. Phellos and $Q$. palustris, while others have designated it as a variety of $Q$. Phellos, Q. coc-
cinea, $Q$. aquatica, $Q$. nigra, and $Q$. imbricaria. It is cinea, Q. aquatica, Q. nigra, and Q. imbricaria. It is
notable that of the botanists who ascribed a hybrid notable that of the botanists who ascribed a hybrid
origin to the plant, all agreed that $Q$. Phellos must be one of the parents, a fact which will be easily explainable when an examination of its leaves is made. In October, 1905, the author was accompanied to a locality on Staten Island by Dr. Hollick and Dr. Britton, where several trees of the species had been under observation by them for many years. About 75 acorns
were procured from a tree which bore leaves of a form approximating that of $D$, Fig. 3 , and were placed in
Garden, with the result that 55 plantlets were avail able for study in December and January following. With the formation of the earliest leaves it became
evident that a wide diversity of form of these organs and of other qualities prevailed, as shown by the photograph taken in April.

In May, 1906, all of the plantlets were transferred to a plantation in the experimental grounds, and as development proceeded the diversity became still more marked. At the close of the season it could be seen
that this group of plants included some which simulated $Q$. Phellos with its lanceolate entire leaves, while others were not separable from $Q$. rubra, the remainder being capable of arrangement in a series between these two poles. An examination of the literature disclosed the fact that the combined observations of the severa botanists who have written on the subject refer to
plants bearing almost the entire range of leaves noted in the cultures ants bearing almost counts the leaves are said to be much like those of Q. Phellos, while some observations include notices of others which were broad, lobed, and notched, although most of these writers were extremely chary of identifying any of the forms with those of Q. rubra. It is to be noted, however, that as a result of the con-
sideration of gross anatomical facts and distributional sideration of gross anatomical facts and distributional curred in the general conclusion that the tree was in all probability a hybrid between the red oak and the willow oak.

With our present available information concerning the behavior of hybrids this conclusion seems unavoidable. If we attempt to follow out the history of the
hybridization as it may have occurred, however, we are compelled to rely upon inference in part. The actual nature of the immediate product of the cross is not known. The parental species have undoubtedly sustained similar distributional relations to each other there is no reason to suppose that hybridization may 
not have taken place many generations ago. On this account it is not possible to say whether the tree from which the germinated acorns were taken was the im
mediate product of the cross or whether it is the $n$th generation of its progeny.

In balanced crosses in which the parents show large number of dissimilar characters the first genera tion rarely offers the spectacle of pure dominance of the characters derived from one parent and recessiveness of those from the other parent. It is only when a point or twe gention or the immediate product of the cross resembles one parent or the other, and its progeny split in the next generation. In cases such as that under discussion, and which is also illustrated by the walnuts, the first generation shows a mixed dominance as well as a possible fractionization of some meristic qualities, so that the hybrid appears as an intermediate between the two may be variously estimated. In the second generation the movements of the recessives coupled with the range of fluctuating variability should give a wide diversity of types, varying in number with the number of differentiating points of the parents of the cross which may include both parents, the type of the firs generation, and

By rear of the number of dissimilar character involved in such a cross the probability of deriving an individual composed entirely of recessive characters or of the particular combination characteristic of either ancestor is very small. A progeny of hundreds of thousands of species would be necessary to furnish
a series inclusive of both ancestors and intermediate

While it may not be said that any of the plantlets of the progeny under observation are reconstituted ancestral forms, yet some of the individuals include so many of the qualities of the red oak and willow oak

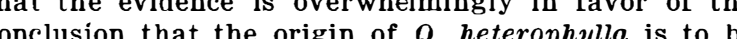
attributed to the hybridization of these two forms. Taking this conclusion as established, it may then be said that the name Q. heterophylla is at present ap plied to a medley of oak trees which possibly includes the first generation of a cross between $Q$. rubra an well as binations of ancestral qualities may appear.

Another aspect of the parental form of the above hybrid and the progeny remains to be mentioned. A which the parental forms come into contact, who gathered a full series of material from the trees available would have data upon which mistaken conclusions as to intergradation of species by fluctuating variability might be made. This leads to the suggestion that any supposed intergradation of two species of seed plant
should be examined with respect to possible hybrid izations before any final estimate is reached in the matter.

Furthermore, it is to be seen that while in all rea sonable probability opportunity for hybridization be tween these two oaks has been present for a period of unknown but undoubted great length, yet it has not resulted in anything in the way of occurrence or distribution suggestive of the disappearance of either parental form. The probably greater frequency of
intra-specific fertilization over hybridization would secure this result. Then again it is to be seen that even in the case of complete cross fertilization of al of the individuals, there would be the probable $r$ genies.

Quercus Rudkini has long been reputed to be hybrid between $Q$. Phellos and $Q$. Marylandica, and a visit was made to the group of trees from which the species was. originally described by Dr. Britton, in company with him and other botanists in October since the original discovery in 1881 others have been he southwestward in New also to some distance distributional relations together with the anatomical features offered by the bark and leaves led to the description of these trees as being of a hybrid origin from the willow oak and the black oak. If these facts only are taken into account, it seems quite a plausible to regard this tree as a hybrid of $Q$. hetero showed a range of forms that included the type of $Q$. $P$ hellos, but did not go wide enough to show duplicates of those of the other parent as described and figured The acorns likewise ranged from the form of $Q$. Phellos toward $Q$. Marylandica, but included none that might be mistaken for the latter. The bark of the various individuals on the other hand seemed most like $Q$. Marylandica, although much variation was apparent.

During the visit of 1905 acorns were found on trees of some of the types only, and material capable these were at the end of the first year's growth, which began in the propagating houses in January in 1900 and ended in September, it was seen that the progenies of the three parents, selected for their dissimilarity, were fairly identical; and while a wide range of variability was found, yet this range did no
exceed the limits of similar fluctuations offered by other spectes of oaks which are known to be unifie hereditary strains.
The leaves of these seedlings did not include forms which might be mistaken for those of either parent It is to be seen therefore that the cultural observations revealed no evidence to show that Rudkin's oak is of hybrid origin, although it did not disprove it. Synthetic tests, which take much time, and detailed anatomical examinations are yet to be resorted to. It is quite possible that the group of trees examined may represent some segregation of the ancestral qualitie . niscovered in . heterophylla. Meanwhile this oak, which is thus constant in successive generations within the limits of its variability, must be regarded as a species in some positive evidence to the contrary is obtained.

The principles illustrated by the foregoing facts ma briefly summarized as follows:

It is obvious that the facts of geographical distribution may be relied upon to furnish conclusive evidence as to the origin of a species or a hereditary quality only under very exceptional conditions in which othe possibilities are excluded, and then only in a circum stantial manner. It is of course a basal and necessary fact that species not in contact may not hybridize,

the converse is true only when otherwise proven.

So far as the plants of suspected hybrid origin from parents suggested by distributional relations are concerned, the methods of investigation available are two conclusive value, while the third may bring no more than confirmations and suggestions.

Attempts at synthesization, if successful, yield de pendable conclusions as to the composition of a hybrid, yet a failure to secure a form by synthesis may be hybridinnate and almost intangible difficulties in the hybridization of the forms concerned, by the different physiological attributes of elementary species include under one name. Furthermore, the natural form th ancestry of which is under search may have been derived hybrid which became fixed in the $n$th generation by a fortuitous combination of dominant char acters. To secure a similar result in an experim test might be beyond the range of probability.

In an anatomical examination such a combination of dominant and recessive characters with fluctuations in meristic characters away beyond either parent may make the results of but little value until confirmed by data derived from

A study of a fixed hybrid by cultural tests of it progeny will reveal nothing as to its origin, and synthesization and anatomic examinations are the only recourse. On the other hand, if the progeny exhibits alternative inheritance,' its components may show unmistakably the nature of the original cross.

The last-named method demonstrates beyond reasonable doubt that Bartram's oak is a hybrid derivative of the willow oak and red oak, the progeny being some of the qualities, and fractionization of others in stead of being a unified hereditary strain. Some of the plantlets included in a progeny of 55 individuals were apparent re-constitutions of the ancestral type were variously intermediate.

Rudkin's oak on the contrary yields no evidence in cultures of its progeny on which a defensible conclusion as to its origin may be based. The individual variability of the trees included under this name is very great, and some of these approach the willow oak in leaf form, and some of the characters of the acorns. The study of over a hundred plantlets showed a wide and practically identical range of variation. Alternative inheritance could not be traced. The individuals known under the name of $Q$. Rudkini produce a large froportion of imperfect acorns, but beyond this no the anatomical resemblances noted.

A list of the natural plant hybrids of North America was prepared by Mr. David George for presentation the International Hybrid Conference in New York in 1902 but was not published. In this list it was noted that 117 natural hybrids had been reported a addition to the indigenous fora of North America, in mosses. The some instances among the ferns an disposal by the director of the New Y ork Botanical Garden, a revision of the list has been made, some of the original references being omitted and a few added. No attempt has been made to make it actually complete, the sole purpose being to suggest material for
extended observations similar to those described in this pape

The reported hybrids are distributed among the natural families as follows:

Naidacex. Two cases in Potamogeton.

Juneraceæ. Twelve hybrids in Carex.
One hybrid, between Juncus effusus and J. Pacificus.

Liliaceæ. One hybrid between Calochortus Ben tham $\imath$ and B. albus.

hybrid between Habenaria lacera and $H$. psycodes.

Juglandaceæ. Three hybrids of Hicoria pecan with H. minima, $H$. alba, and $H$. laciniosa

One hybrid between Juglans nigra and J. cinerea. re noted.

Two hybrids of Betula are also reported between $B$. pumila and $B$, lenta and between $B$. populifolia and $B$. papyrifera.

Fagaceæ. Thirty-five oak hybrids have been report-

ed, but one of these, Q. Rudkini, has been tested as Ranunculave with negative results. A. ruora. Clematis viornoides is reported to be of hybrid nature.

Cruciferæ. Roripa palustris is supposed to torm natural hybrids with $R$. obtusa and $R$. sinuata.

Pomaceæ. Malus Soulardi is taken to be a cross ers. osed to form a hybrid.

Papilionaceæ. A hybrid between Baptısia australis and $B$. bracteata is reported.

Anacardiaceæ. Rhus hirta is supposed to cross with R. glabra.

Rhamnaceæ. Ceanothus Lobbianas is taken to be hybrid between $C$. thyrsiforus and $C$. dentatus. It is papillosus and $C$. sorediatus.
poritions

Violaceæ. A large number of hybrids of Vıola have been reported.

Onagraceæ. Oenothera biennis and O. Oakesiana ing of several types.

Cactacex. A hybrid is supposed to be formed be tween two species of Opuntia.

Cornus Baileya has been taken to be a hybrid between $C$. asperifolia and $C$. stolonifera. Verbenaceæ. The evidence seems strong that Ver bena Canadensis and V. bracteosa. V. bracteosa and $V$ and $V$. $V$. bracteosa and V. urticifolia, V. bracteosa $V$. urticifolia, $V$. urticifolia and $V$. hastata, $V$. angust folia and V. stricta, and V. angustifolia and V. brac-

Acanthacex. Ruellia ciliosa parvifora has been upposed to be the result of a cross between $\boldsymbol{R}$. ciliosa and $R$. strepens.

Lobeliaceæ. Lobelia syphilitica is supposed to hybridize with $L$. cardinalis.

Cichoriaceæ. Prenanthes Mainensis is taken to be cross between Nabalus racemosus and N. trifoliatus Solidago, Aster, Bidens and Helenium.

The genera noted above are supposed to offer about two hundred hybrids; and as the observations have been made principally with the flora of eastern North America in a region which probably does not furnish more than twenty thousand species, it is to be seen that the questions involved affect about one per cent of the included in the above list could be confirmed by actual tests, but on the other hand it is probable that a closer examination

Some of the constituents of the native flora are known to be constant unitypic hybrids, and hence have every claim to be regarded as species. The type of trated by Bartram's oak, and between these two diverse modes of action may be found. In gaining a more extended and accurate knowledge of the manner in which the qualities of separate unified strains of plants are alternative, or are interlocked, or fraction gained for the consideration of all questions in gen tions of such characters.-Botanical Gazette.

\section{THE FEAR OF OPEN AND CLOSED SPACES.} By Charles Mercier, M.D.

AgORAPHOBIA, or fear of open spaces, is not nearly as common a malady as its antithesis, claustrophobia Both are curious, and somewhat anomalous, states of mitted by the subject of it to be irrational and absurd nevertheless dominates conduct, prompts the execution of irrational acts, and renders certain rational and desirable acts impossible.

If I had to speculate on the origin of these curious and spurious instincts, for such they may be termed, existed in full force, and had great biological value, irr our remote ancestry, but which in most of us have long been obsolete. When our ancestors were arborea Feeble in body, destitute of weapons and of defensive armor, devoid of means of concealment, their safety from carnivorous foes lay in the agility with which they could climb out of reach, and in the accuracy from tree to tree. Whenever they descended to the ground, they were in danger. It is on the ground that the greater carnivora pursue their prey; and, adapted as our ancestors were to arboreal life, their progress on open ground was undoubtedly less rapid than among the tree tops, and most probably less rapid than that of their principal foes. Among the tree tops they activity, or hope to overtake them; but on the ground they were at a disadvantage. On the flat, they had no chance against the spring of the panther or th speed and wind of the wolf; but once let them attain chatter with contempt at their helpless enemies below. The farther they ventured from their secure retreat the greater the peril they were in: the nearer their
refuge, the more complete their sense of security. Since 